\title{
New voltage-mode universal filter and sinusoidal oscillator using only single DBTA
}

HERENCSÁR, N.; KOTON, J.; VRBA, K.; LATTENBERG, I.

International Journal of Electronics

2010, vol. 97, iss. 4, pp. 365-379

ISSN (Print): 0020-7217

ISSN (Online): 1362-3060

DOI: http://dx.doi.org/10.1080/00207210903325229

Accepted manuscript

This is an Accepted Manuscript of an article published by Taylor \& Francis in International Journal of Electronics on 01 Apr 2010, available online: http://www.tandfonline.com/10.1080/00207210903325229 


\title{
New voltage-mode universal filter and sinusoidal oscillator using only single DBTA
}

\author{
Norbert Herencsár*, Jaroslav Koton, Kamil Vrba and Ivo Lattenberg \\ Department of Telecommunications, Faculty of Electrical Engineering and \\ Communication, Brno University of Technology, Purkynova 118, \\ 612 00 Brno, Czech Republic
}

(Received 26 March 2009; final version received 30 July 2009)

\begin{abstract}
In this paper, a new voltage-mode second-order universal frequency filter and sinusoidal oscillator using only single differential-input buffered and transconductance amplifier (DBTA) is presented. Proposed voltage-mode filter structure using single DBTA and four passive elements can provide all standard filter functions, i.e. low-, band-, high-pass, band-stop, and all-pass without changing the circuit topology and enables independent control of the quality factor $Q$ using single passive element. The circuit requires the minimal number of active and passive elements with no conditions for component matching. By slight modification of the proposed filter structure, the new DBTA-based sinusoidal oscillator is easily obtained. The oscillation condition and the oscillation frequency are independently adjustable by different virtually grounded passive elements. The proposed sinusoidal oscillator employs only grounded capacitors. The passive and active sensitivities of all the proposed circuit configurations are low. PSPICE simulations using a BJT realization of DBTA and experimental results based on commercially available amplifiers OPA860 and MAX436 are included, which prove the workability of the proposed circuits.
\end{abstract}

Keywords: active filter; analogue signal processing; universal frequency filter; differential-input buffered and transconductance amplifier (DBTA); voltage-mode; sinusoidal oscillator

\section{Introduction}

Frequency filters and sinusoidal oscillators are linear electric circuits (Toumazou et al. 1990) that are used in wide area of electronics and also are the basic building blocks in analogue signal processing. The analogue frequency filters are the most often used as anti-aliasing video filters in the analogue sections of high-speed data communication systems defined by ITU BT 601 standard (Uygur and Kuntman 2007) or for signal processing in wireless LANs described by IEEE 802.11 standard (Lo et al. 2009), in IF (intermediate frequency) receiver stages of the GSM cellular telephones (Fabre et al. 1997, Ibrahim et al. 2005), in receiver baseband blocks of modern radio systems (Rudell et al. 1997, Toker et al. 2001), in hard-drive communication interfaces (Laber and Gray 1993), measurement systems (Vainio and Ovaska 1997), automotive industry (Ferri and Guerrini 2003), or in piezoresistive pressure sensors (Samitier et al. 1998). Oscillators also represent an important unit in many telecommunication, instrumentation and control systems (Holzel 1993, Ahmed et al. 1997,

\footnotetext{
*Corresponding author. Email: herencsn@feec.vutbr.cz
} 
Cam et al. 1998, Cicekoglu and Toker 1999, Soliman 1999, Khan and Khwaja 2000, Abuelma'atti and Al-Absi 2005, Horng et al. 2005).

The presented structures of active frequency filters and oscillators are often employing current conveyors (CCs), where the second-generation current conveyor (CCII) (Sedra and Smith 1970) is the most popular. The CCII is the basic block of many other active elements. Here, the current-feedback operational amplifier (CFOA) (Evans 1988, Svoboda et al. 1991, Fabre 1992, Liu 1995, Soliman 1996) that is a combination of the CCII and voltage follower (VF) (Sedra 1972) or the modified CFOA (MCFOA) that is the interconnection of the plus-type and minus-type CCIIs (Yuce and Minaei 2008) can be mentioned. Later, the inverting second-generation CC (ICCII) as a missing building block in analogue signal processing techniques has been introduced (Awad and Soliman 1999). By the combination of CCII and ICCII the dual-X second-generation CC (DXCCII) (Zeki and Toker 2002) for the tuneable continuous-time filter design has been built. Recently, further research has focused on CCs with variable current and/or voltage gains such as electronically tuneable second-generation current conveyor (ECCII) (Minaei et al. 2006), variable gain current conveyor (VGCCII) (Yuce et al. 2008), or voltage and current gain second generation current conveyor (VCG-CCII) (De Marcellis et al. 2009).

Using the duality principle, the voltage conveyor (VC) has been presented (Dostal and Pospisil 1982a). As in the theory of current conveyors, also here the first- and second-generation VCs (VCI, VCII, IVCI, and IVCII) were described (Dostal and Pospisil 1982b, Novotny and Vrba 2003, Minarcik and Vrba 2006). The best known is the plus-type differential current voltage conveyor (DCVC+) (Salama and Soliman 1999) that is more often labelled as the current differencing buffered amplifier (CDBA) (Acar and Ozoguz 1999). By the modification of the CDBA or replacement of the VF by the operational transconductance amplifier (OTA) (Geiger and Sanchez-Sinencio 1985) the differential-input current feedback amplifier (DCFA) (Zeki et al. 2001), current differencing transconductance amplifier (CDTA) (Biolek 2003), and current follower transconductance amplifier (CFTA) (Herencsar et al. 2008a, Herencsar et al. 2008b) or inverted current follower transconductance amplifier (ICFTA) (Herencsar et al. 2008c) have been presented.

Based on the idea of the "universal" active element (Carlosena et al. 1994) the universal current conveyor (UCC) was designed and developed (Becvar et al. 2000, Cajka et al. 2004, Herencsar and Vrba 2007, Jerabek and Vrba 2009), and produced by AMI Semiconductor Czech, Ltd., (now ON Semiconductor Czech Republic, Ltd.) in the CMOS $0.35 \mu \mathrm{m}$ technology under the designation UCC-N1B 0520. Through suitable interconnection or grounding of the terminals, the UCC enables realization of all types and generations of $\mathrm{CCs}$ with single current input $\mathrm{X}$ (Becvar et al. 2000). On the basis of the UCC, the universal voltage conveyor (UVC) was designed (Novotny and Vrba 2003, Cajka and Vrba 2004, Minarcik and Vrba 2008, Koton et al. 2009) and produced under the designation UVC-N1C 0520. The realizable generations and types of VCs using the UVC were shown by Minarcik and Vrba (2006).

There is still a need to develop new filter and oscillator structures with new active elements that offer new advantages. In this paper, the application possibilities of the differential-input buffered and transconductance amplifier (DBTA) (Herencsar et al. 2009) for the design of frequency filter and oscillator are presented. The proposed voltage-mode (VM) filter employs only single DBTA and four passive elements. All standard filter functions without changing the circuit topology can be realized. Furthermore, independent control of the quality factor $Q$ via single 
passive element is enabled. The presented circuit requires minimal number of active and passive elements with no conditions for component matching. By a simple modification of the proposed filter structure, novel DBTA-based sinusoidal oscillator is obtained. In the oscillator structure all passive elements are grounded, which makes the circuit attractive for VLSI. The oscillation condition and the oscillation frequency are independently adjustable by the passive elements. PSPICE simulations and experimental results based on commercially available amplifiers OPA860 and MAX436 are included to verify the theoretical conclusions of the proposed circuits.

\section{Description of the DBTA}

The schematic symbol and internal structure of the DBTA (differential-input buffered and transconductance amplifier) (Herencsar et al. 2009) is shown in Figure 1. It has low-impedance current inputs $p, n$ and high-impedance voltage input $y$. The difference of the $i_{\mathrm{p}}$ and $i_{\mathrm{n}}$ currents flows from auxiliary terminal $z$. The voltage $v_{\mathrm{z}}$ on this terminal is transferred into output terminal $w$ using the VF and also transformed into current using the transconductance $g_{\mathrm{m}}$, which flows into output terminal $x$. Relations between the individual terminals of the DBTA can be described by following hybrid matrix:

$$
\left[\begin{array}{c}
v_{\mathrm{p}} \\
v_{\mathrm{n}} \\
i_{\mathrm{y}} \\
i_{\mathrm{z}} \\
v_{\mathrm{w}} \\
i_{\mathrm{x}}
\end{array}\right]=\left[\begin{array}{cccccc}
0 & 0 & 1 & 0 & 0 & 0 \\
0 & 0 & 1 & 0 & 0 & 0 \\
0 & 0 & 0 & 0 & 0 & 0 \\
1 & -1 & 0 & 0 & 0 & 0 \\
0 & 0 & 0 & 1 & 0 & 0 \\
0 & 0 & 0 & \pm g_{\mathrm{m}} & 0 & 0
\end{array}\right]\left[\begin{array}{c}
i_{\mathrm{p}} \\
i_{\mathrm{n}} \\
v_{\mathrm{y}} \\
v_{\mathrm{z}} \\
i_{\mathrm{w}} \\
v_{\mathrm{x}}
\end{array}\right]
$$

The possible bipolar implementation of the DBTA is shown in Figure 2. The differential-input stage is formed by transistors $Q_{1}-Q_{29}$, transistors $Q_{30}-Q_{35}$ form the VF, and the OTA consists of transistors $Q_{36}-Q_{39}$. In the design the transistor model parameters NR100N (NPN) and PR100N (PNP) of bipolar arrays ALA400 from AT\&T were used (Frey 1993). Bias current $I_{\mathrm{O}}=400 \mu \mathrm{A}$ has been chosen. The transconductance $g_{\mathrm{m}}$ of DBTA can be set by current $I_{\mathrm{B}}=2 g_{\mathrm{m}} V_{\mathrm{T}}$, where $V_{\mathrm{T}}$ is the thermal voltage (approximately $26 \mathrm{mV}$ at $27^{\circ} \mathrm{C}$ ). The parasitic elements of the proposed DBTA in Figure 2 have been computed using PSPICE simulation program. The parasitic elements in Figure 3 are computed as $C_{\mathrm{p} 1}=C_{\mathrm{n} 1}=C_{\mathrm{w} 1}=3.08 \mathrm{pF}, C_{\mathrm{p} 2}=2.73 \mathrm{pF}, C_{\mathrm{n} 2}=2.64 \mathrm{pF}, C_{\mathrm{y}}=4.41 \mathrm{pF}$, $C_{\mathrm{z}}=2.04 \mathrm{pF}, C_{\mathrm{w} 2}=1.65 \mathrm{pF}, C_{\mathrm{x}}=1.06 \mathrm{pF}, L_{\mathrm{p}}=L_{\mathrm{n}}=119.91 \mathrm{nH}, L_{\mathrm{w}}=112.03 \mathrm{nH}$, $R_{\mathrm{p} 1}=R_{\mathrm{n} 1}=2.84 \mathrm{k} \Omega, R_{\mathrm{p} 2}=R_{\mathrm{n} 2}=R_{\mathrm{w} 2}=39.34 \Omega, R_{\mathrm{p} 3}=R_{\mathrm{n} 3}=205.67 \Omega$, $R_{\mathrm{y}}=34.17 \mathrm{k} \Omega, R_{\mathrm{z}}=228.21 \mathrm{k} \Omega, R_{\mathrm{w} 1}=1.09 \mathrm{k} \Omega, R_{\mathrm{w} 3}=281.37 \Omega, R_{\mathrm{x}}=1.49 \mathrm{M} \Omega$. The maximum values of terminal voltages and terminal currents without producing significant distortion are computed as $\pm 365 \mathrm{mV}$ and $\pm 605 \mu \mathrm{A}$, respectively. The dc voltage gains $\beta_{\mathrm{p}} \cong \beta_{\mathrm{n}} \cong 0.961$ and $\gamma \cong 0.962$ with bandwidths $f_{\beta \mathrm{p}} \cong f_{\beta \mathrm{n}} \cong 381.1 \mathrm{MHz}$ and $f_{\gamma} \cong 417.1 \mathrm{MHz}$. The dc current gains $\alpha_{\mathrm{p}} \cong \alpha_{\mathrm{n}} \cong 0.989$ with bandwidths $f_{\alpha \mathrm{p}} \cong 170.9 \mathrm{MHz}$ and $f_{\alpha \mathrm{n}} \cong 173.9 \mathrm{MHz}$. The transconductance $g_{\mathrm{m}} \cong 0.951 \mathrm{mS}$ with the bandwidth $f_{g \mathrm{~m}} \cong 85.8 \mathrm{MHz}$. 


\section{Proposed universal filter structure}

The proposed VM second-order frequency filter employing single DBTA and four passive elements is shown in Figure 4. Even if all passive elements are shown as floating, which might be not attractive for integration (Bhusan and Newcomb 1967, Abuelma'atti et al. 1995), it should be mentioned that unused voltage inputs are always grounded, as described below.

The output voltages $\boldsymbol{V}_{o 1}$ and $\boldsymbol{V}_{o 2}$ of this circuit are given by the relations:

$$
\begin{gathered}
\boldsymbol{V}_{o 1}=\frac{1}{\Delta}\left[G_{1} g_{\mathrm{m}} \boldsymbol{V}_{i 1}+s C_{2} G_{2} \boldsymbol{V}_{i 2}+\boldsymbol{s}^{2} C_{1} C_{2} \boldsymbol{V}_{i 3}-s C_{2} g_{\mathrm{m}} \boldsymbol{V}_{i 4}\right], \\
\boldsymbol{V}_{o 2}=\frac{1}{\Delta}\left[\begin{array}{c}
-\left(s C_{1} G_{1}+G_{1} G_{2}\right) \boldsymbol{V}_{i 1}+G_{1} G_{2} \boldsymbol{V}_{i 2}+ \\
+s C_{1} G_{1} \boldsymbol{V}_{i 3}+\left(\boldsymbol{s}^{2} C_{1} C_{2}+s C_{2} G_{2}\right) \boldsymbol{V}_{i 4}
\end{array}\right],
\end{gathered}
$$

where

$$
\Delta=s^{2} C_{1} C_{2}+s C_{2} G_{2}+G_{1} g_{\mathrm{m}}
$$

For the proposed filter depending on the status of circuit input four voltages $\boldsymbol{V}_{i 1}, \boldsymbol{V}_{i 2}, \boldsymbol{V}_{i 3}$ and $\boldsymbol{V}_{i 4}$ numerous filter functions are obtained. Based on the output selected there are two cases show as presented below:

Case $I$. If the $\boldsymbol{V}_{o}=\boldsymbol{V}_{o 1}$ is used as output, then from (2) the realizable transfer functions in voltage mode are:

(i) If $\boldsymbol{V}_{i 2}=\boldsymbol{V}_{i 3}=\boldsymbol{V}_{i 4}=0$ (grounded), a low-pass filter (LP1) can be obtained with $\boldsymbol{V}_{o} / \boldsymbol{V}_{i 1}$

(ii) If $\boldsymbol{V}_{i 1}=\boldsymbol{V}_{i 3}=\boldsymbol{V}_{i 4}=0$ (grounded), a band-pass filter (BP1) can be obtained with $\boldsymbol{V}_{o} / \boldsymbol{V}_{i 2}$;

(iii) If $\boldsymbol{V}_{i 1}=\boldsymbol{V}_{i 2}=\boldsymbol{V}_{i 4}=0$ (grounded), a high-pass filter (HP1) can be obtained with $\boldsymbol{V}_{o} / \boldsymbol{V}_{i 3}$;

(iv) If $\boldsymbol{V}_{i 1}=\boldsymbol{V}_{i 2}=\boldsymbol{V}_{i 3}=0$ (grounded), a band-pass filter (BP2) can be obtained with $\boldsymbol{V}_{o} / \boldsymbol{V}_{i 4}$

(v) If $\boldsymbol{V}_{i 2}=\boldsymbol{V}_{i 4}=0$ (grounded) and $\boldsymbol{V}_{i 1}=\boldsymbol{V}_{i 3}=\boldsymbol{V}_{i n}$, a band-stop filter (BS) can be obtained with $\boldsymbol{V}_{o} / \boldsymbol{V}_{\text {in }}$

(vi) If $\boldsymbol{V}_{i 1}=0$ (grounded) and $\boldsymbol{V}_{i 2}=\boldsymbol{V}_{i 3}=\boldsymbol{V}_{i 4}=\boldsymbol{V}_{i n}$, an all-pass (AP) can be obtained with $\boldsymbol{V}_{o} / \boldsymbol{V}_{i n}$.

In this case the proposed circuit is universal and can provide all standard types of filter functions, i.e. low-, band-, high-pass, band-stop, and an all-pass response without changing the circuit topology.

Case II. If the $\boldsymbol{V}_{o}=\boldsymbol{V}_{o 2}$ is used as output, then from (3) the realizable transfer functions in voltage mode are:

(vii) If $\boldsymbol{V}_{i 1}=\boldsymbol{V}_{i 3}=\boldsymbol{V}_{i 4}=0$ (grounded), a low-pass filter (LP2) can be obtained with $\boldsymbol{V}_{o} / \boldsymbol{V}_{i 2}$

(viii) If $\boldsymbol{V}_{i 1}=\boldsymbol{V}_{i 2}=\boldsymbol{V}_{i 4}=0$ (grounded), a band-pass filter (BP3) can be obtained with $\boldsymbol{V}_{o} / \boldsymbol{V}_{i 3}$

(ix) If $\boldsymbol{V}_{i 3}=0$ (grounded) and $\boldsymbol{V}_{i 1}=\boldsymbol{V}_{i 2}=\boldsymbol{V}_{i 4}=\boldsymbol{V}_{i n}$, a high-pass filter (HP2) can be obtained with $\boldsymbol{V}_{o} / \boldsymbol{V}_{i n}$.

Thus, the circuit is multifunction and it is capable of realizing low-, bandand high-pass response without changing the circuit topology. In case of HP2 re- 
sponse the proposed circuit requires component matching conditions $C_{1}=C_{2}$ and $G_{1}=G_{2}$.

For all filters the natural frequency $\omega_{0}$, quality factor $Q$ and bandwidth BW derived from (4) are:

$$
\omega_{0}=\sqrt{\frac{G_{1} g_{\mathrm{m}}}{C_{1} C_{2}}}, Q=\frac{1}{G_{2}} \sqrt{\frac{C_{1} G_{1} g_{\mathrm{m}}}{C_{2}}}, \mathrm{BW}=\frac{\omega_{0}}{Q}=\frac{G_{2}}{C_{1}} .
$$

Note that the quality factor $Q$ can be controlled independently of natural frequency $\omega_{0}$ by $G_{2}$. By replacing appropriate conductor by FET-based voltagecontrolled resistor (VCR) (Hribsek and Newcomb 1976, Senani 1994), the quality factor $Q$ can be controlled electronically that is particular advantage of the proposed circuit. The natural frequency $\omega_{0}$ can be independently adjusted from the bandwidth, by varying $C_{2}, G_{1}$ or $g_{\mathrm{m}}$ of the proposed frequency filter. Here, the appropriate capacitor can be replaced by a voltage-controlled capacitor (VCC) (Newcomb 1981, Lee et al. 2008) or by digitally-controlled varactor (DCV) (Chen et al. 2005) for electronical control of the natural frequency $\omega_{0}$ independently from the bandwidth.

The relative sensitivities of the $\omega_{0}, Q$ and BW parameters of the designed circuit derived from (5) are:

$$
\begin{gathered}
S_{G_{1}, g_{\mathrm{m}}}^{\omega_{0}}=-S_{C_{1}, C_{2}}^{\omega_{0}}=\frac{1}{2}, \quad S_{G_{2}}^{\omega_{0}}=0, \\
S_{C_{1}, G_{1}, g_{\mathrm{m}}}^{Q}=-S_{C_{2}}^{Q}=\frac{1}{2}, \quad S_{G_{2}}^{Q}=-1, \\
S_{G_{2}}^{\mathrm{BW}}=-S_{C_{1}}^{\mathrm{BW}}=1, \quad S_{C_{2}, G_{1}, g_{\mathrm{m}}}^{\mathrm{BW}}=0 .
\end{gathered}
$$

From the results it is evident that the sensitivities are low and not larger than unity of absolute value.

Taking into account the non-idealities of DBTA, the relationship of the terminal currents and voltages given in (1) can be rewritten as:

$$
\left[\begin{array}{c}
v_{\mathrm{p}} \\
v_{\mathrm{n}} \\
i_{\mathrm{y}} \\
i_{\mathrm{z}} \\
v_{\mathrm{w}} \\
i_{\mathrm{x}}
\end{array}\right]=\left[\begin{array}{cccccc}
0 & 0 & \beta_{\mathrm{p}} & 0 & 0 & 0 \\
0 & 0 & \beta_{\mathrm{n}} & 0 & 0 & 0 \\
0 & 0 & 0 & 0 & 0 & 0 \\
\alpha_{\mathrm{p}} & -\alpha_{\mathrm{n}} & 0 & 0 & 0 & 0 \\
0 & 0 & 0 & \gamma & 0 & 0 \\
0 & 0 & 0 & \pm g_{\mathrm{m}} & 0 & 0
\end{array}\right]\left[\begin{array}{c}
i_{\mathrm{p}} \\
i_{\mathrm{n}} \\
v_{\mathrm{y}} \\
v_{\mathrm{z}} \\
i_{\mathrm{w}} \\
v_{\mathrm{x}}
\end{array}\right],
$$

where $\alpha_{\mathrm{p}}=1-\varepsilon_{\mathrm{i}}, \alpha_{\mathrm{n}}=1-\varepsilon_{\mathrm{i}}$ and $\varepsilon_{\mathrm{i}}\left(\left|\varepsilon_{\mathrm{i}}\right| \ll 1\right)$ are the current tracking errors from $p$ and $n$ terminals to $z$ terminal, $\beta_{\mathrm{p}}=1-\varepsilon_{\mathrm{v}}, \beta_{\mathrm{n}}=1-\varepsilon_{\mathrm{v}}$ and $\varepsilon_{\mathrm{v}}\left(\left|\varepsilon_{\mathrm{v}}\right| \ll 1\right)$ are the voltage tracking errors from $p$ and $n$ terminals to $z$ terminal and $\gamma=1-\varepsilon_{\mathrm{v}}$ and $\varepsilon_{\mathrm{v}}\left(\left|\varepsilon_{\mathrm{v}}\right| \ll 1\right)$ is the voltage tracking error from $z$ terminal to $w$ terminal of DBTA, respectively. The transconductance $g_{\mathrm{m}}$ of the OTA with the non-idealities can be assumed as (Tsukutani et al. 2006, Chen et al. 2008):

$$
g_{\mathrm{m}}=\frac{g_{\mathrm{m}} \omega_{g}}{s+\omega_{g}} \cong g_{\mathrm{m}}(1-\mu \boldsymbol{s})
$$


where $\omega_{g}$ is the first-pole of the OTA and $\mu=1 / \omega_{g}$. Taking into account nonidealities of the DBTA mentioned above, the denominator of (2), (3) becomes:

$$
\Delta=s^{2} C_{1} C_{2}+s C_{2} G_{2}\left(1-\frac{\alpha_{\mathrm{n}} \beta_{\mathrm{n}} G_{1} g_{\mathrm{m}} \mu}{C_{2} G_{2}}\right)+\alpha_{\mathrm{n}} \beta_{\mathrm{n}} G_{1} g_{\mathrm{m}} .
$$

Due to the parasitic effect, the characteristic departs from the ideal responses. But, the parasitic effect can be made negligible satisfying the following condition:

$$
\frac{\alpha_{\mathrm{n}} \beta_{\mathrm{n}} G_{1} g_{\mathrm{m}} \mu}{C_{2} G_{2}} \ll 1
$$

\section{Proposed sinusoidal oscillator}

From the filter structure in Figure 4, by setting $\boldsymbol{V}_{i 1}=\boldsymbol{V}_{i 2}=\boldsymbol{V}_{i 3}=\boldsymbol{V}_{i 4}=0$ (grounded) and connecting the capacitor $C_{3}$ to terminal $p$ of the DBTA, a single DBTA-based sinusoidal oscillator can be obtained as shown in Figure 5.

In this case, the characteristic equation of the proposed configuration can be given by:

$$
\boldsymbol{s}^{2} C_{1} C_{2}+\boldsymbol{s}\left(C_{2} G_{2}-C_{3} g_{\mathrm{m}}\right)+G_{1} g_{\mathrm{m}} .
$$

The oscillation condition and oscillation frequency $\omega_{0}$ of this circuit can be obtained as:

$$
C_{2} G_{2}=C_{3} g_{\mathrm{m}},
$$

and

$$
\omega_{0}=\sqrt{\frac{G_{1} g_{\mathrm{m}}}{C_{1} C_{2}}} .
$$

It should be noted that the condition of oscillator (12) can be controlled through adjusting the value of the conductor $G_{2}$ and/or the capacitor $C_{3}$ without affecting the oscillation frequency $\omega_{0}(13)$. Analogously, oscillation frequency $\omega_{0}$ can be adjusted by controlling the value of the conductor $G_{1}$ and/or the capacitor $C_{1}$ without affecting the oscillation condition. Similarly, as the frequency filter, the oscillation condition and oscillation frequency of this solution might be adjusted using FET-based VCRs (Hribsek and Newcomb 1976, Senani 1994).

The active and passive sensitivities of the proposed oscillator are low, not larger than unity of absolute value and are obtained as:

$$
S_{G_{1}, g_{\mathrm{m}}}^{\omega_{0}}=-S_{C_{1}, C_{2}}^{\omega_{0}}=\frac{1}{2}
$$

and

$$
S_{G_{2}, C_{3}}^{\omega_{0}}=0
$$




\section{Simulation and measurement results}

Using the bipolar implementation of the DBTA (Figure 2), the proposed universal filter structure (Case $I$ ) has been designed for characteristic frequency $f_{0} \approx 1 \mathrm{MHz}$ and the quality factor of filters $Q=1$, and simulated in PSPICE software. The following values have been chosen: $C_{1}=C_{2}=150 \mathrm{pF}, G_{1}=G_{2}=1 \mathrm{mS}$ $\left(R_{1}=R_{2}=1 \mathrm{k} \Omega\right)$ and $g_{\mathrm{m}}=1 \mathrm{mS}\left(I_{\mathrm{B}}=50 \mu \mathrm{A}\right)$. For the practical measurements the DBTA has been implemented by using commercially available amplifiers, as shown in Figure 6. The simulation and measurement results of the low- (LP1), band- (BP2), high-pass (HP1), band-stop (BS), and all-pass (AP) frequency filter working in voltage mode are shown in Figure 7 and Figure 8. Simulation and measurement results of the band-pass filter BP1 working in voltage mode are shown in Figure 9. Here, the possibility of adjusting the quality factor $Q$ is demonstrated. For required values $Q=\{0.3 ; 1 ; 3 ; 10 ; 30\}$ the conductivity must be $G_{2}=\{3.333$; $1.000 ; 0.333 ; 0.100 ; 0.033\} \mathrm{mS}\left(R_{2}=\{0.3 ; 1 ; 3 ; 10 ; 30\} \mathrm{k} \Omega\right)$. From the results it is evident that the results of the measurements are in agreement with the simulations. In the higher-frequency region the real properties of the OPA860, MAX436 amplifiers and parasitic capacities or inductances of the constructed prototypes begin to be more significant.

In order to confirm the above given theoretical analysis, the proposed DBTAbased sinusoidal oscillator in Figure 5 has also been simulated using PSPICE software. The DBTA model, using commercially available amplifiers OPA860 and MAX436, illustrated in Figure 6 has been used with the supply voltages of $\pm 5 \mathrm{~V}$. To obtain the sinusoidal output waveform with the oscillation frequency of $f_{0}=\omega_{0} / 2 \pi \cong 15.92 \mathrm{kHz}$, the following passive component values have been chosen: $G_{1}=G_{2}=0.1 \mathrm{mS}\left(R_{1}=R_{2}=10 \mathrm{k} \Omega\right), g_{\mathrm{m}}=0.1 \mathrm{mS}, C_{1}=C_{2}=C_{3}=1 \mathrm{nF}$ where $G_{2} \cong 93.46 \mu \mathrm{S}\left(R_{2} \cong 10.7 \mathrm{k} \Omega\right)$ was designed to be smaller than $g_{\mathrm{m}}$ to ensure the oscillations would start. The simulated sinusoidal output $\boldsymbol{V}_{o}$ of the proposed oscillator is shown in Figure 10 (a). From the simulation results, the oscillation frequency of $f_{0} \cong 15.88 \mathrm{kHz}$ is obtained, which is slightly lower than theoretical oscillation frequency. Figure 10 (b) shows the simulated frequency spectrum of $\boldsymbol{V}_{o}$. The total harmonic distortion (THD) is equal to $2.069 \%$, and the results are summarized in Table 1 . The control of $f_{0}$ via $G_{1}$ without affecting the oscillation condition is shown in Figure 11.

\section{Conclusion}

In this paper, the application possibilities of the novel versatile active function block for analogue signal processing, namely the differential-input buffered and transconductance amplifier (DBTA), have been demonstrated in voltage-mode universal filter and sinusoidal oscillator design. The DBTA consists of differential-input stage, voltage follower and operational transconductance amplifier. The possible implementation of the DBTA by commercially available active elements and its possible internal bipolar structure have been shown. Proposed VM universal filter structure using only single DBTA and four passive elements provides all standard filter functions (LP, BP, HP, BS, and AP) without changing the circuit topology and enables independent control of the quality factor $Q$ via single passive element. The circuit requires minimal number of active and passive elements with no conditions for component matching. Furthermore, a single DBTA-based sinusoidal oscillator can be easily obtained by a slight modification of the proposed single DBTA-based filter. Its oscillation condition and oscillation frequency can be controlled separately via different grounded conductor and/or capacitor. In addition, the sensitivities of all 
proposed circuits are low. From simulation and measurement results it is evident that the final solution corresponds to theoretical expectations and the DBTA appears as very useful active function block for analogue frequency filter and oscillator design.

\section{Acknowledgments}

The paper has been supported by the Czech Science Foundation project GACR 102/09/1681 and Ministry of Education of the Czech Republic project No. MSM0021630513. The authors also would like to thank the anonymous reviewers for their helpful comments, which substantially improved the quality of this paper.

\section{References}

[1] Abuelma'atti, M.T., Al-Ghumaiz, A.A., and Khan, M.H. (1995) 'Novel CCIIbased single-element controlled oscillators employing grounded resistors and capacitors', International Journal of Electronics, 78, 1107-1112.

[2] Abuelma'atti, M.T., and Al-Absi, M.A. (2005) 'A current conveyor-based relaxation oscillator as a versatile electronic interface for capacitive and resistive sensors', International Journal of Electronics, 92, 473-477.

[3] Acar, C., and Ozoguz, S. (1999), 'A new versatile building block: current differencing buffered amplifier suitable for analog signal processing filters', Microelectronics Journal, 30, 157-160.

[4] Ahmed, M.T., Khan, I.A., and Minhaj, N. (1997), 'On transconductance-C quadrature oscillators', International Journal of Electronics, 83, 201-207.

[5] Awad, I.A., and Soliman, A.M. (1999), 'Inverting second generation current conveyors: the missing building blocks, CMOS realizations and applications', International Journal of Electronics, 86, 413-432.

[6] Becvar, D., Vrba, K., Zeman, V., and Musil, V. (2000), 'Novel universal active block: a universal current conveyor', in Proceedings of the IEEE International Symposium on Circuits and Systems - ISCAS'00, Geneva, Switzerland, pp. 471-474.

[7] Bhusan, M., and Newcomb, R.W. (1967) 'Grounding of capacitors in integrated circuits', Electronics Letters, 3, 148-149.

[8] Biolek, D. (2003), 'CDTA - building block for current-mode analog signal processing', in Proceedings of the 16th European Conference on Circuit Theory and Design - ECCTD'03, Krakow, Poland, pp. 397-400.

[9] Cajka, J., and Vrba, K. (2004), 'The voltage conveyor may have in fact found its way into circuit theory', AEU - International Journal of Electronics and Communications, 58, 244-248.

[10] Cajka, J., Dosta, T., and Vrba, K. (2004), 'General view on current conveyors', International Journal of Circuit Theory and Applications, 32, 133-138.

[11] Cam, U., Kuntman, H., and Acar, C. (1998), 'On the realization of OTA-C oscillators', International Journal of Electronics, 85, 313-326.

[12] Carlosena, A., Cabeza, R., and Serrano, L. (1994), 'On the search for a universal active element', in Proceedings of the IEEE International Symposium on Circuits and Systems - ISCAS'94, London, UK, pp. 779-782.

[13] Chen, H.P., Shen, S.S., and Wang, J.P. (2008), 'Electronically tunable versatile voltage-mode universal filter', $A E U$ - International Journal of Electronics and Communications, 62, 316-319. 
[14] Chen, P.-L., Chung, C.-C., and Lee, C.-Y. (2005), 'A portable digitally controlled oscillator using novel varactors', IEEE Transactions on Circuits and Systems - II, 52, 233-237.

[15] Cicekoglu, O., and Toker, A. (1999), 'Current-mode oscillator with linear period control over a wide range', International Journal of Electronics, 86, 14531462.

[16] De Marcellis, A., Ferri, G., Guerrini, N.C., Scotti, G., Stornelli, V., and Trifiletti, A. (2009), 'The VCG-CCII: a novel building block and its application to capacitance multiplication', Analog Integrated Circuits and Signal Processing, $58,55-59$.

[17] Dostal, T., and Pospisil, J. (1982a), 'Current and voltage conveyors - a family of three port immittance converters', in Proceedings of the IEEE International Symposium on Circuits and Systems - ISCAS'82, Roma, Italy, pp. 419-422; (1982b), 'Hybrid models of 3-port immittance convertors and current and voltage conveyors', Electronics Letters, 18, 887-888.

[18] Evans, S. (1988), Current Feedback Op-amp Applications Circuit Guide, Fort Collins, CO: Complinear Corp., 11.20-11.26.

[19] Fabre, A. (1992), 'Gyrator implementation from commercially available transimpedance operational amplifier', Electronics Letters, 28, 263-264.

[20] Fabre, A., Saaid, O., Wiest, F., and Boucheron, C. (1997), 'Low power currentmode second-order bandpass IF filter', IEEE Transactions on Circuits and Systems-II, 44, 436-446.

[21] Ferri, G., and Guerrini, N.C. (2003), Low-Voltage Low-Power CMOS Current Conveyors, London: Kluwer Acad. Publ.

[22] Frey, D.R. (1993), 'Log-domain filtering: an approach to current-mode filtering', IEE Proceedings G-Circuits, Devices and Systems, 140, 406-416.

[23] Geiger, R.L., and Sanchez-Sinencio, E. (1985), 'Active filter design using operational transconductance amplifiers: a tutorial', IEEE Circuits and Devices Magazine, 1, 20-32.

[24] Herencsar, N., and Vrba, K. (2007), 'Current conveyors-based circuits using novel transformation method', IEICE Electronics Express, 4, 650-656.

[25] Herencsar, N., Koton, J., Vrba, K., and Lattenberg, I. (2008a), 'Novel SIMO type current-mode universal filter using CFTAs and CMIs', in Proceedings of the 31th International Conference on Telecommunications and Signal Processing - TSP'08, Paradfurdo, Hungary, pp. 107-110.

[26] Herencsar, N., Koton, J., Lattenberg, I., and Vrba, K. (2008b), 'Signal-flow graphs for current-mode universal filter design using current follower transconductance amplifiers (CFTAs)', in Proceedings of the Applied Electronics - APPEL'08, Pilsen, Czech Republic, pp. 113-116.

[27] Herencsar, N., Koton, J., Vrba, K., Lattenberg, I., and Misurec, J. (2008c), 'Generalized design method for voltage-controlled current-mode multifunction filters', in Proceedings of the 16th Telecommunications forum - TELFOR'08, Belgrade, Serbia, pp. 400-403.

[28] Herencsar, N., Vrba, K., Koton, J., and Lattenberg, I. (2009), 'The conception of differential-input buffered and transconductance amplifier (DBTA) and its application', IEICE Electronics Express, 6, 329-334.

[29] Holzel, R. (1993), 'A simple wide-band sine wave quadrature oscillator', IEEE Transactions on Instrumentation and Measurement, 42, 758-760.

[30] Horng, J.W., Hou, C.L., Chang, C.M., Chung, W.Y., Tang, H.W., and Wen, Y.H. (2005), 'Quadrature oscillators using CCIIs', International Journal of Electronics, 92, 21-31.

[31] Hribsek, M., and Newcomb, R.W. (1976), 'VCO controlled by one variable 
resistor', IEEE Transactions on Circuits and Systems, 23, 166-169.

[32] Ibrahim, M.A., Minaei, S., and Kuntman, H. (2005), 'A 22.5 MHz currentmode KHN-biquad using differential voltage current conveyor and grounded passive elements', AEU - International Journal of Electronics and Communications, 59, 311-318.

[33] Jerabek, J., and Vrba, K. (2009), 'SIMO type low-input and high-output impedance current-mode universal filter employing three universal current conveyors', AEU - International Journal of Electronics and Communications, Article in Press, DOI: 10.1016/j.aeue.2009.03.002.

[34] Khan, I.A., and Khwaja, S. (2000), 'An integrable Gm-C quadrature oscillator', International Journal of Electronics, 87, 1353-1357.

[35] Koton, J., Vrba, K., and Herencsar, N. (2009), 'Tuneable filter using voltage conveyors and current active elements', International Journal of Electronics, $96,787-794$.

[36] Laber, C.A., and Gray, P.R. (1993), 'A 20-MHz sixth-order BiCMOS parasiticinsensitive continuous-time filter and second-order equalizer optimized for disk-drive read channels', IEEE Journal of Solid-State Circuits, 28, 462-470.

[37] Lee, A., Ko, H., Cho, D.D., and Hwang, G. (2008), 'Non-ideal behavior of a driving resonator loop in a vibratory capacitive microgyroscope', Microelectronics Journal, 39, 1-6.

[38] Liu, S.-I. (1995), 'Universal filter using two current-feedback amplifiers', Electronics Letters, 31, 629-630.

[39] Lo, T.Y., Kao, C.S., and Hung, C.C. (2009), 'A Gm-C continuous-time analog filter for IEEE $802.11 \mathrm{a} / \mathrm{b} / \mathrm{g} / \mathrm{n}$ wireless LANs', Analog Integrated Circuits and Signal Processing, 58, 197-204.

[40] Minaei, S., Sayin, O.K., and Kuntman, H. (2006), 'A new CMOS electronically tunable current conveyor and its application to current-mode filters', IEEE Transactions on Circuits and Systems - I, 53, 1448-1457.

[41] Minarcik, M., and Vrba, K. (2006), 'Low-output and high-input impedance frequency filters using universal voltage conveyor for high-speed data communication systems', in Proceedings of the IARIA 5th International Conference on Networking - ICN'06, Mauritius, pp. 1-4.

[42] Minarcik, M., and Vrba, K. (2008), 'Single-input six-output voltage-mode filter using Universal Voltage Conveyors', IEICE Transactions on Fundamentals, E91-A, 2035-2037.

[43] Newcomb, R.W. (1981), 'The semistate description of nonlinear time-variable circuits', IEEE Transactions on Circuits and Systems, 28, 62-71.

[44] Novotny, V., and Vrba, K. (2003), 'Applications with voltage conveyors', in Proceedings of the 2nd WSEAS International Conference on Electronics, Control and Signal Processing - ICECS'03, Singapore, pp. 1-4.

[45] Rudell, J.C., Ou, J.J., Cho, T.B., Chien, G., Brianti, F., Weldon, J.A., and Grey, P. (1997), 'A 1.9-GHz wide-band IF double conversion CMOS receiver for cordless telephone applications', IEEE Journal of Solid-State Circuits, 32, 2071-2088.

[46] Salama, K., and Soliman, A. (1999), 'Novel MOS-C quadrature oscillator using the differential current voltage conveyor', in Proceedings of the 42nd Midwest Symposium on Circuits and Systems - MWSCAS'99, Las Cruces, USA, pp. 279-282.

[47] Samitier, J., Puig-Vidai, M., Bota, S.A., Rubio, C., Siskos, S.K., and Laopoulos, T. (1998), 'A current-mode interface circuit for a piezoresistive pressure sensor', IEEE Transactions on Instrumentation and Measurement, 47, 708710 . 
[48] Sedra, A.S. (1972), 'A class of stable active filters using unity-gain voltage followers', IEEE Journal of Solid-State Circuits, 7, 311-315.

[49] Sedra, A., and Smith, K.C. (1970), 'A second-generation current conveyor and its applications', IEEE Transactions on Circuit Theory, 17, 132-134.

[50] Senani, R. (1994), 'Realization of linear voltage-controlled-resistance in floating form', Electronics Letters, 30, 1909-1911.

[51] Soliman, A.M, (1996), 'Applications of the current feedback operational amplifiers', Analog Integrated Circuits and Signal Processing, 11, 265-302.

[52] Soliman, A.M. (1999), 'Synthesis of grounded capacitor and grounded resistor oscillators', Journal of the Franklin Institute, 336, 735-746.

[53] Svoboda, J.A., McGory, L., and Webb, S. (1991), 'Applications of a commercially available current conveyor', International Journal of Electronics, 70, 159-164.

[54] Toker, A., Cicekoglu, O., Ozcan, S., and Kuntman, H. (2001), 'High-outputimpedance transadmittance type continuous-time multifunction filter with minimum active elements', International Journal of Electronics, 88, 10851091.

[55] Toumazou, C., Lidgey, F.J., and Haigh, D.G. (1990), Analogue IC Design: The current-mode approach, London: Peter Peregrinus Ltd.

[56] Tsukutani, T., Edasaki, S., Sumi, Y., and Fukui, Y. (2006), 'Current-mode universal biquad filter using OTAs and DO-CCII', Frequenz, 60, 237-240.

[57] Uygur, A., and Kuntman, H. (2007), 'Seventh-order elliptic video filter with 0.1 dB pass band ripple employing CMOS CDTAs', AEU - International Journal of Electronics and Communications, 61, 320-328.

[58] Yuce, E., and Minaei, S. (2008), 'A modified CFOA and its applications to simulated inductors, capacitance multipliers, and analog filters', IEEE Transactions on Circuits and Systems - I, 55, 266-275.

[59] Yuce, E., Pal, K., and Minaei, S. (2008), 'A high input impedance voltagemode all-pass/notch filter using a single variable gain current conveyor', Journal of Circuits, Systems, and Computers, 17, 827-834.

[60] Vainio, O., and Ovaska, S.J. (1997), 'A class of predictive analog filters for sensor signal processing and control instrumentation', IEEE Transactions on Industrial Electronics, 44, 565-578.

[61] Zeki, A., and Toker, A. (2002), 'The dual-X current conveyor (DXCCII): a new active device for tunable continuous-time filters', International Journal of Electronics, 89, 913-923.

[62] Zeki, A., Toker, A., and Ozoguz, S. (2001), 'Linearly tunable transconductor using modified CDBA', Analog Integrated Circuits and Signal Processing, 26, $179-183$. 


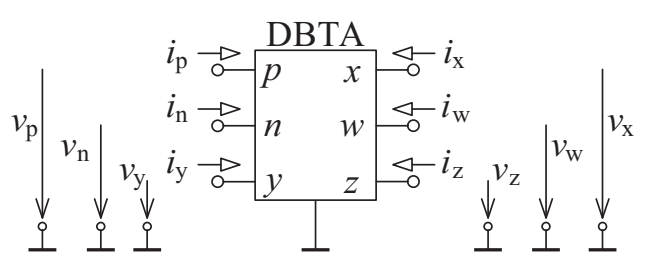

(a)

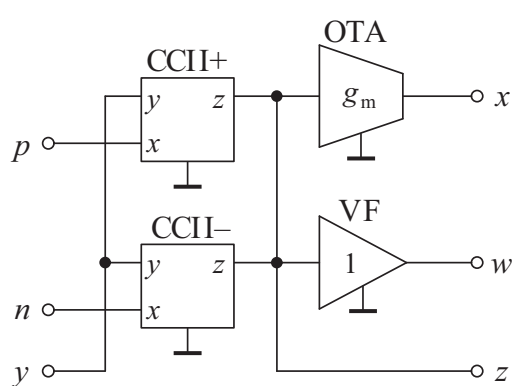

(b)

Figure 1. (a) Schematic symbol of DBTA, (b) internal structure of DBTA.

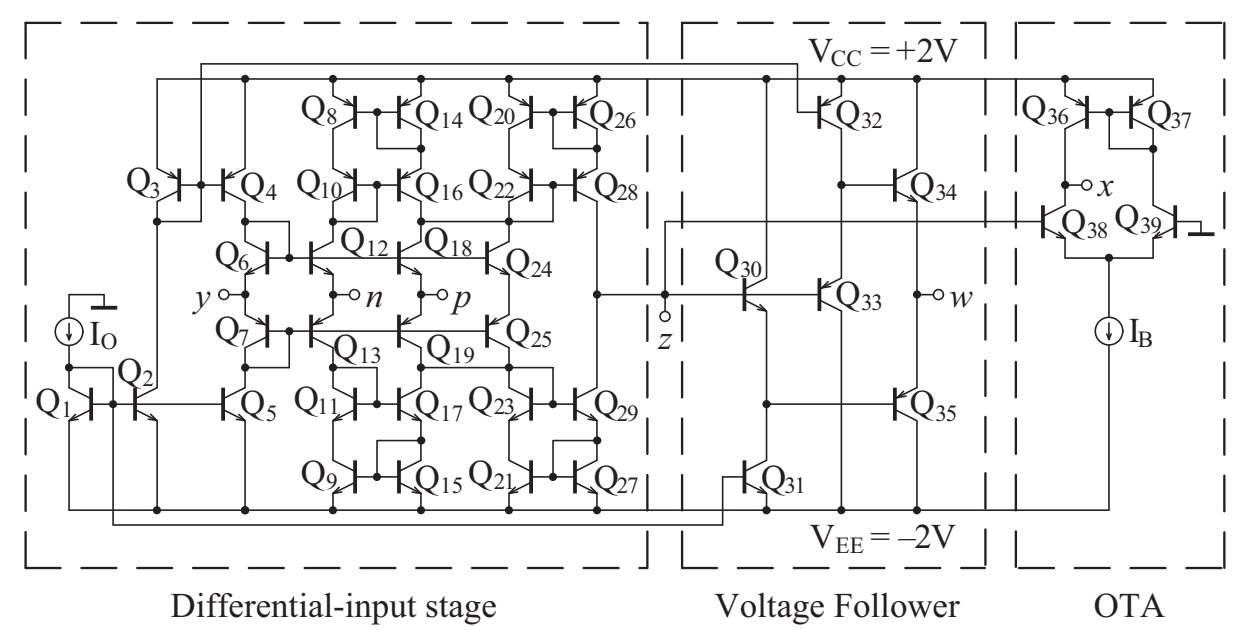

Figure 2. Bipolar implementation of the DBTA.

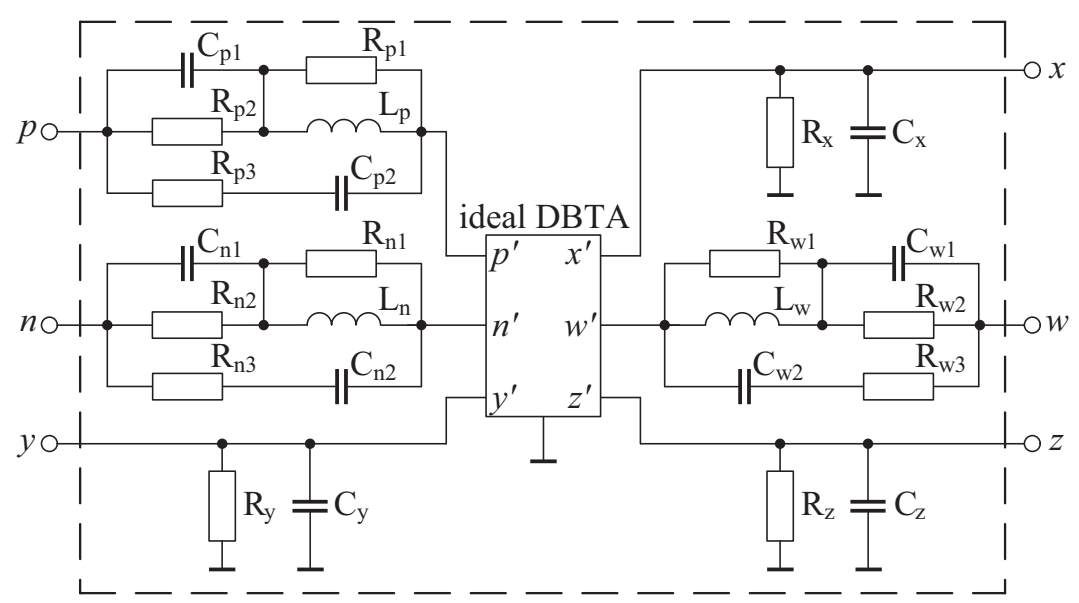

Figure 3. Model of the DBTA including parasitic elements. 


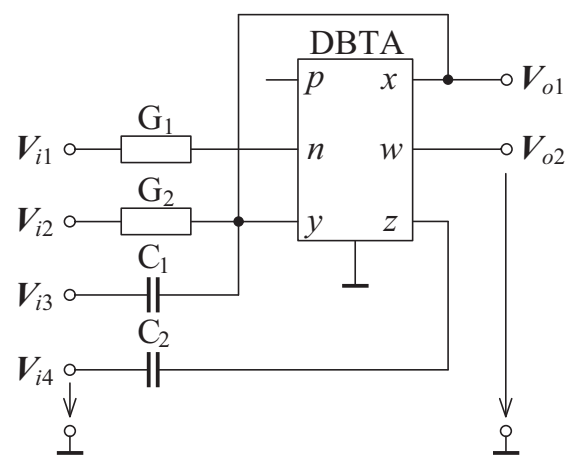

Figure 4. Proposed voltage-mode universal filter using single DBTA.

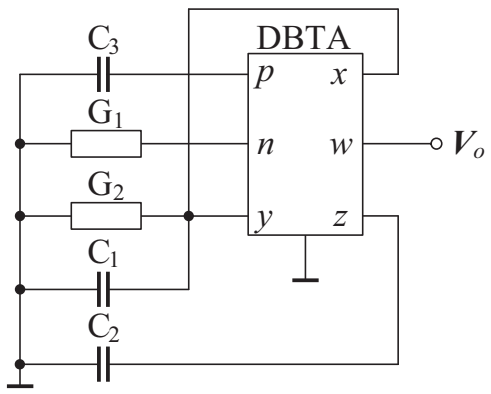

Figure 5. Proposed single DBTA-based sinusoidal oscillator.

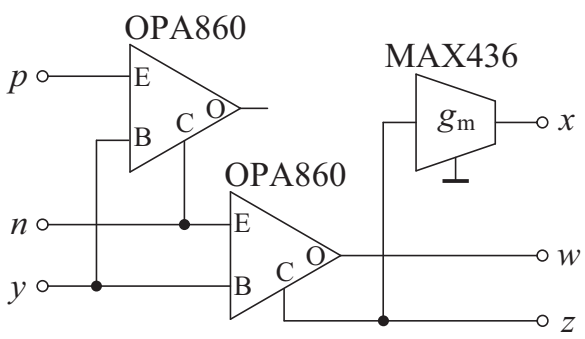

Figure 6. Possible realization of DBTA by commercially available amplifiers OPA860 and MAX436.

Table 1. Total harmonic distortion analysis of the DBTA-based oscillator in Figure 5.

\begin{tabular}{llllll}
\hline $\begin{array}{l}\text { Harmonic } \\
\text { no. }\end{array}$ & $\begin{array}{l}\text { Frequency } \\
(\mathrm{Hz})\end{array}$ & $\begin{array}{l}\text { Fourier } \\
\text { component }\end{array}$ & $\begin{array}{l}\text { Normalized } \\
\text { component }\end{array}$ & $\begin{array}{l}\text { Phase } \\
(\mathrm{Deg})\end{array}$ & $\begin{array}{l}\text { Normalized } \\
\text { phase }\end{array}$ \\
\hline 1 & $1.592 \mathrm{E}+04$ & $2.529 \mathrm{E}-01$ & $1.000 \mathrm{E}+00$ & $1.049 \mathrm{E}+02$ & $0.000 \mathrm{E}+00$ \\
2 & $3.184 \mathrm{E}+04$ & $3.450 \mathrm{E}-03$ & $1.364 \mathrm{E}-02$ & $1.142 \mathrm{E}+02$ & $-9.565 \mathrm{E}+01$ \\
3 & $4.776 \mathrm{E}+04$ & $1.149 \mathrm{E}-03$ & $4.544 \mathrm{E}-03$ & $-1.793 \mathrm{E}+02$ & $-4.941 \mathrm{E}+02$ \\
4 & $6.368 \mathrm{E}+04$ & $2.558 \mathrm{E}-03$ & $1.012 \mathrm{E}-02$ & $5.882 \mathrm{E}+01$ & $-3.609 \mathrm{E}+02$ \\
5 & $7.960 \mathrm{E}+04$ & $2.759 \mathrm{E}-03$ & $1.091 \mathrm{E}-02$ & $3.901 \mathrm{E}+01$ & $-4.856 \mathrm{E}+02$ \\
\hline \multicolumn{4}{l}{ DC component $=1.085017 \mathrm{E}-02$} & &
\end{tabular}

DC component $=1.085017 \mathrm{E}-02$

Total harmonic distortion $=2.069141 \mathrm{E}+00$ PERCENT 


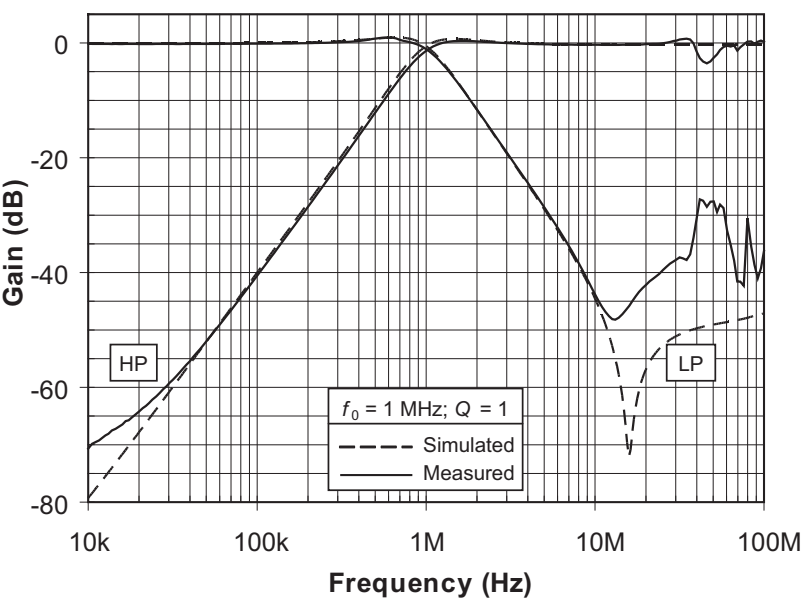

(a)

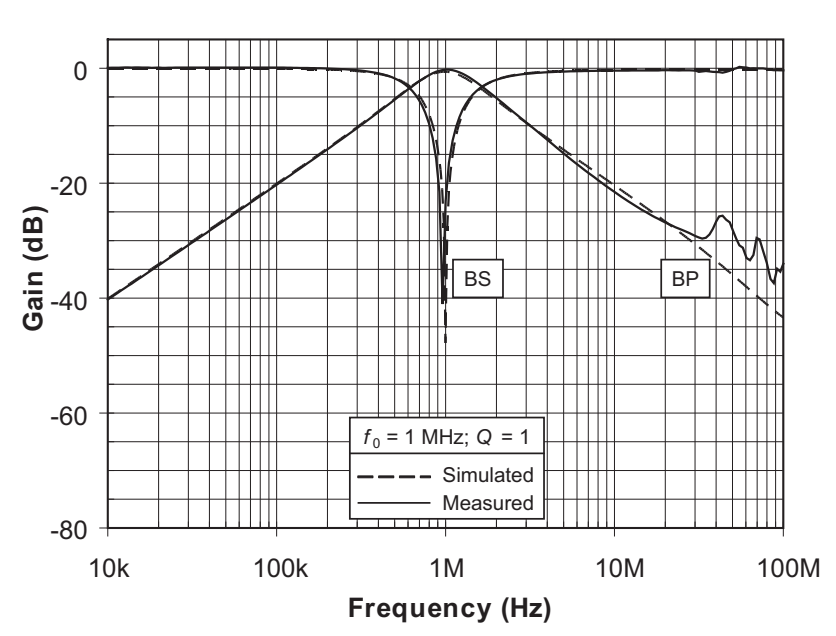

(b)

Figure 7. Simulated and measured frequency characteristics for: (a) LP1 and HP1, (b) BP2 and BS responses of the proposed circuit of Figure 4. 


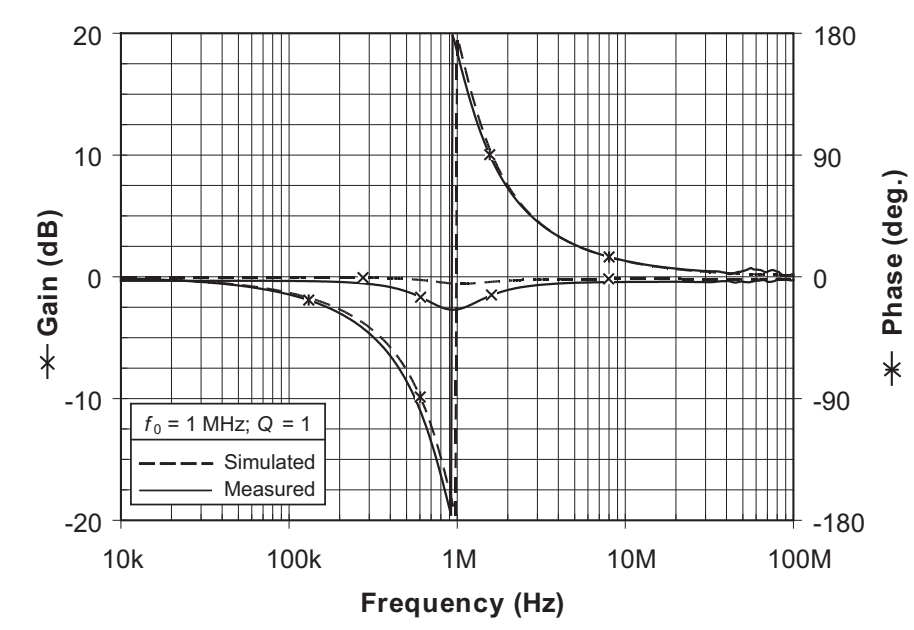

(a)

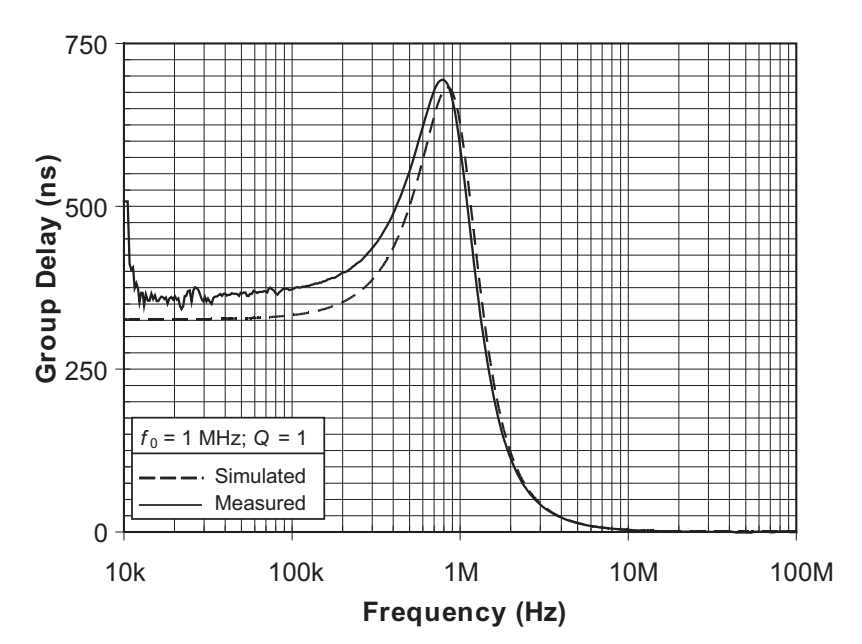

(b)

Figure 8. Simulated and measured frequency responses of the all-pass (AP) filter: (a) gain and phase responses, (b) group delay response.

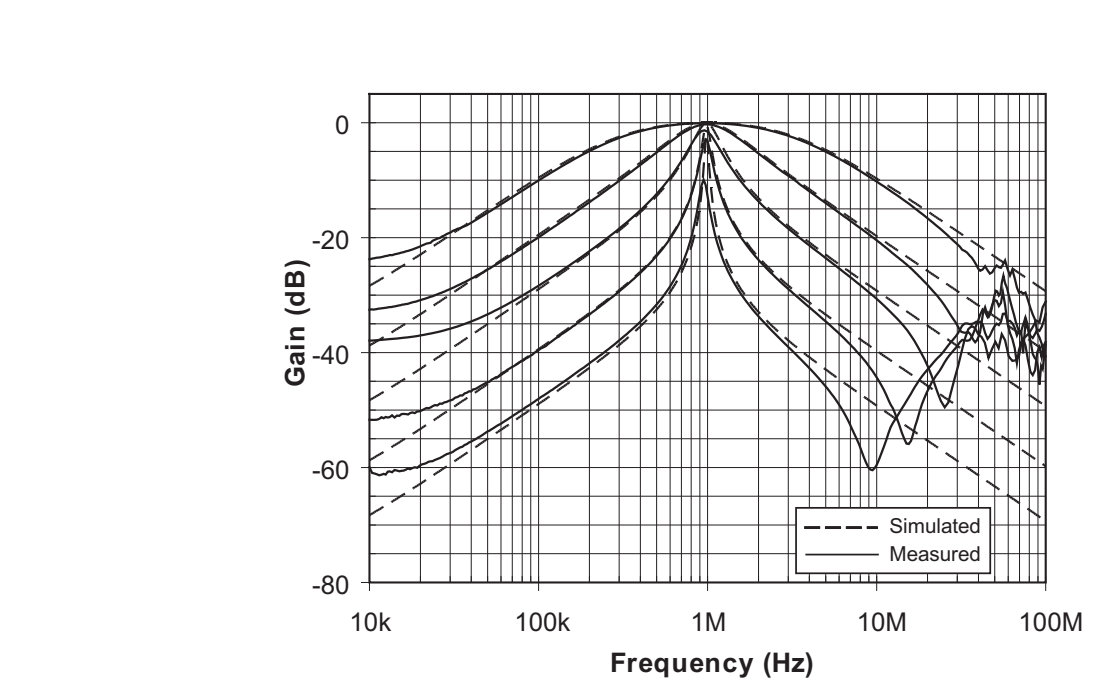

Figure 9 . Simulated and measured results of proposed voltage-mode band-pass filter (BP1) for values of
quality factor $Q=\{0.3 ; 1 ; 3 ; 10 ; 30\}$.

Figure 9 . Simulated and measured results of proposed voltage-mode band-pass filter (BP1) for values of
quality factor $Q=\{0.3 ; 1 ; 3 ; 10 ; 30\}$.

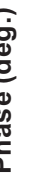

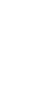




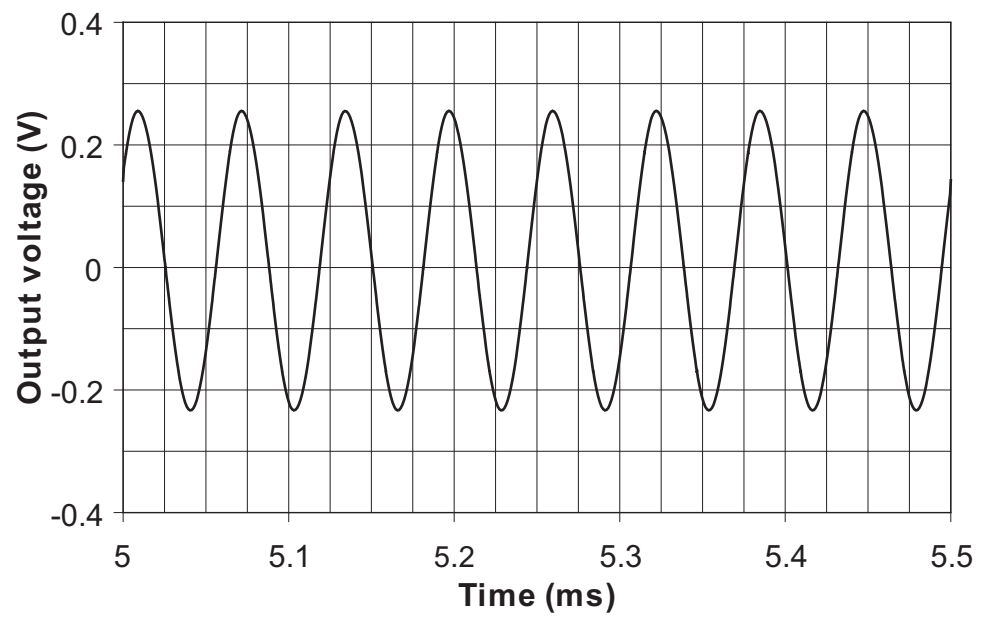

(a)

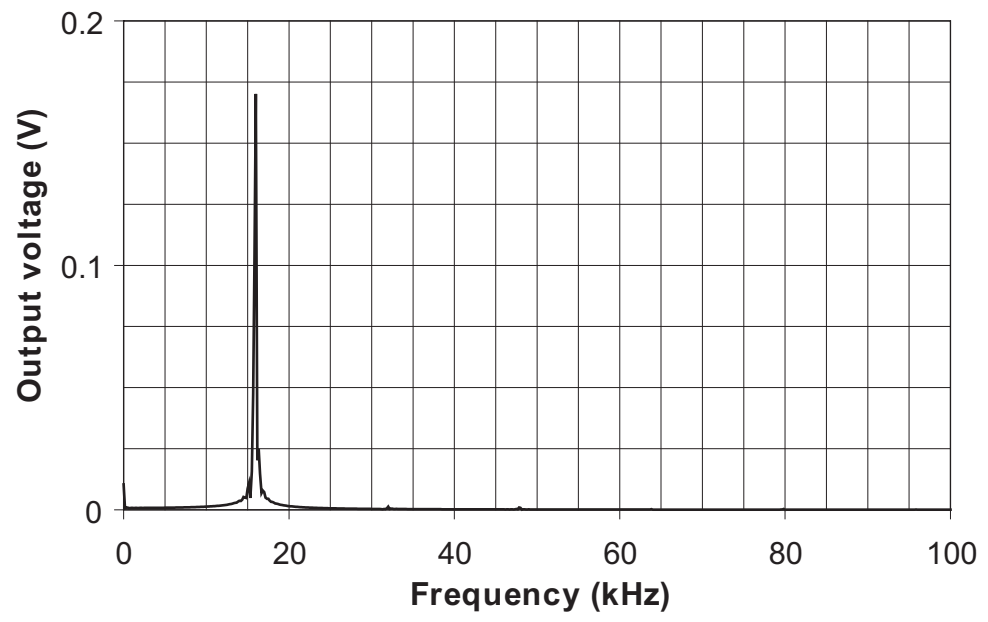

(b)

Figure 10. (a) The simulated waveform output and (b) the simulated frequency spectrum of the proposed oscillator in Figure 5.

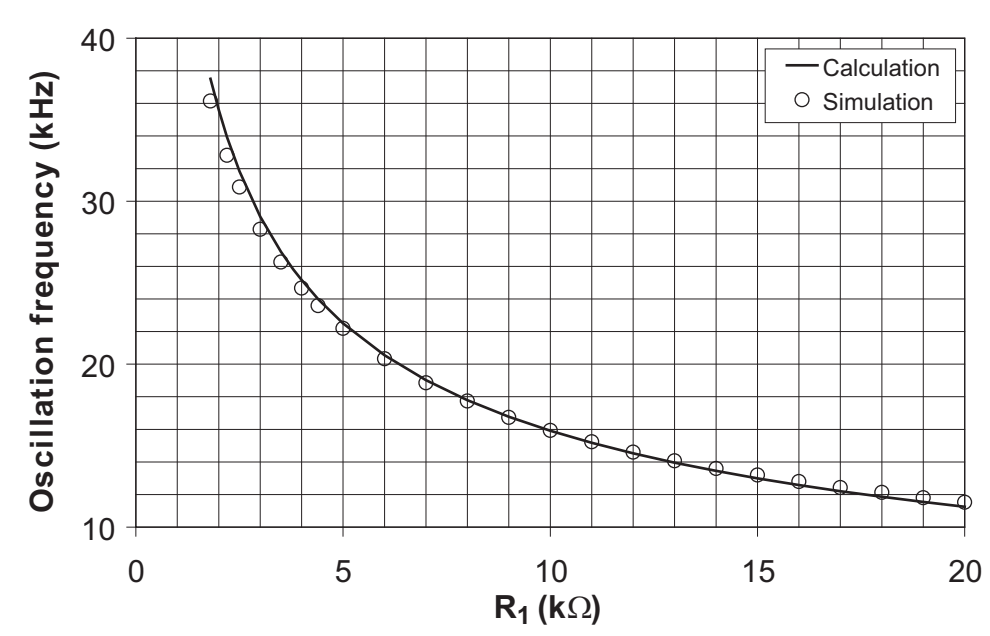

Figure 11. Calculation and simulation results of the oscillation frequencies of $\boldsymbol{V}_{o}$ by varying the value of the $G_{1}$. 